\title{
Effect of Initial Grain Orientation on Evolution of Deformed Microstructure in Hot Compressed Ni-30Fe Alloy
}

\author{
Jae-Young Cho ${ }^{1,2}$, Tadanobu Inoue ${ }^{1}$, Fuxing Yin $^{1}$ and Kotobu Nagai ${ }^{1}$ \\ ${ }^{1}$ Steel Research Center, National Institute for Materials Science, Sengen, Tsukuba 305-0047, Japan \\ ${ }^{2}$ School of Materials Science and Engineering, Seoul National University Shinrim-dong, \\ San 56-1, Kwanak-ku, Seoul 151-742, Korea
}

An experimental procedure has been developed to investigate systematically the effect of initial grain orientation on the evolution of deformed microstructure in $\mathrm{Ni}-30 \mathrm{Fe}$ alloy. The investigation of identical grains before and after hot deformation made it possible to trace the evolution of microstructure deformed up to $50 \%$ at a strain rate of $1 / \mathrm{s}$ in a single pass at $1023 \mathrm{~K}$ using a hot compression simulator. The localized inhomogeneous shear bands occurred in almost all grains. On the other hand, the near $\{110\}\langle 001\rangle$ grains have undergone fairly homogeneous deformation even after a high equivalent plastic strain of 1.9 .

(Received April 6, 2004; Accepted August 12, 2004)

Keywords: nickel-30 ferrous alloy, shear band, hot deformation, electron back-scattering diffraction pattern, Goss orientation

\section{Introduction}

In recent years, two kinds of approaches to ultrafinegrained steels have been suggested. One is the heavy deformation of austenite in non-recrystallized region, which results in the dynamic transformation of unstable austenite to ultrafine ferrite grains ${ }^{1-3)}$ and the other is to introduce the accumulation of strains into ferrite grains by severe warm deformation, which induces the recovered or recrystallized ultrafine ferrite grains. ${ }^{4-7)}$

The key element in the method of heavy deformation of austenite in non-recrystallized temperature region is to increase the density of localized inhomogeneous deformation defects within austenite grains. But it is very difficult to investigate systematically the deformation defects in the austenite of the low carbon steel because the austenite grains are transformed to martensite or bainite during quenching to room temperature.

Since Charnock and Nutting ${ }^{8)}$ reported the stacking fault energy across the iron-nickel system, there have been a number of investigations on the deformed structures of austenite using the austenitic Ni-30Fe alloy which has the stacking fault energy and the deformation characteristics similar to those of low carbon austenite. Hurley et al. ${ }^{9)}$ studied the deformed structures of the austenite through hot compression and torsion tests, and Adachi et al. ${ }^{10)}$ investigated the deformed substructure of austenite by hot compression test of the Ni-30Fe alloy. Recently, Suh et al. ${ }^{11)}$ studied the change of deformed microstructure of austenite at various strains, strain rates and deformation temperatures using the Ni-30Fe alloy.

In general, the subdivision of grains during deformation takes place macroscopically with the formation of shear bands and microscopically with the formation of cell blocks and cells. ${ }^{12)}$ The deformed structures may vary considerably depending on processing variables such as strain, strain rate and deformation temperature and material variables such as stacking fault energy and grain size. Furthermore, considering the crystallographic nature of plastic deformation, the development of deformed microstructure can be greatly affected by the initial grain orientation relative to the imposed deformation conditions. Accordingly, the present work aims to investigate the effect of initial grain orientation on the evolution of the deformed microstructure of the Ni$30 \mathrm{Fe}$ alloy on a macroscopic scale using SEM and EBSD technique.

\section{Experimental}

\subsection{Specimen preparation}

The ingot of $\mathrm{Ni}-30 \mathrm{Fe}$ alloy was prepared in a $50-\mathrm{kg}$ vacuum induction melting furnace. The chemical composition of Ni-30Fe alloy is given in Table 1. The ingot was reheated to $1473 \mathrm{~K}$ and hot rolled to make a plate with a size of $T 60 \times W 140 \times L 550(\mathrm{~mm})$. The final rolling was performed at the temperature of $1243 \mathrm{~K}$. Rectangular specimens that were $12 \mathrm{~mm}$ in thickness, $7.5 \mathrm{~mm}$ in width and $20 \mathrm{~mm}$ in length were machined from the hot rolled plate for hot compression test. Two blocks of specimens were assembled together by bolts and nuts to form a $15 \mathrm{~mm}$ wide specimen as shown in Fig. 2, which made it possible to observe the inner contacting surface after deformation.

\subsection{Hot compression test}

Figure 1 shows the path of the hot compression test. A high temperature deformation simulator (DSI, Gleeble 2000) was used for the thermo-mechanical treatment. The specimen was put into a furnace maintained at $1473 \mathrm{~K}$ and held for 1 hour to allow the initial grain size to grow to about $450 \mu \mathrm{m}$, followed by water quenching to room temperature. Then the specimen was heated to $1023 \mathrm{~K}$ and held for 20 seconds to make the specimen temperature uniform and then deformed by a reduction ratio of $50 \%$ at a strain rate of $1 / \mathrm{s}$. The deformation temperature of $1023 \mathrm{~K}$ is known to be in the non-recrystal-

Table 1 Chemical compositions of specimen (in mass\%).

\begin{tabular}{ccccccc}
\hline $\mathrm{C}$ & $\mathrm{Mn}$ & $\mathrm{Si}$ & $\mathrm{P}$ & $\mathrm{S}$ & $\mathrm{Ni}$ & $\mathrm{Fe}$ \\
\hline 0.002 & $<0.002$ & 0.008 & 0.002 & 0.001 & 69.8 & Bal.
\end{tabular}




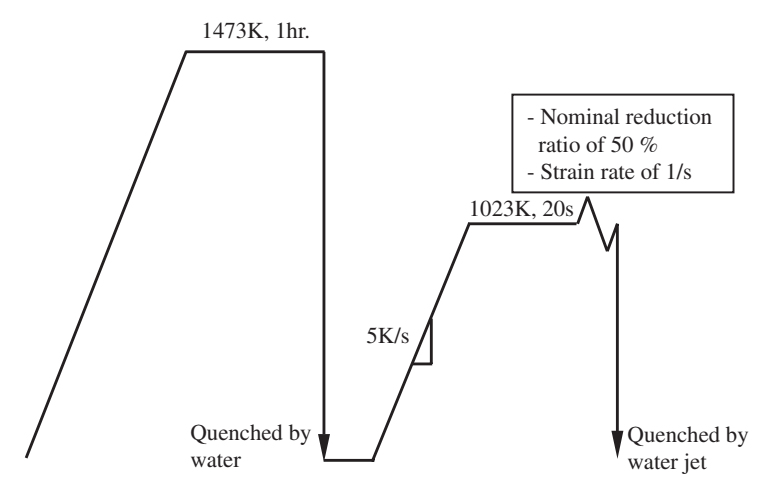

Fig. 1 Hot compression process.

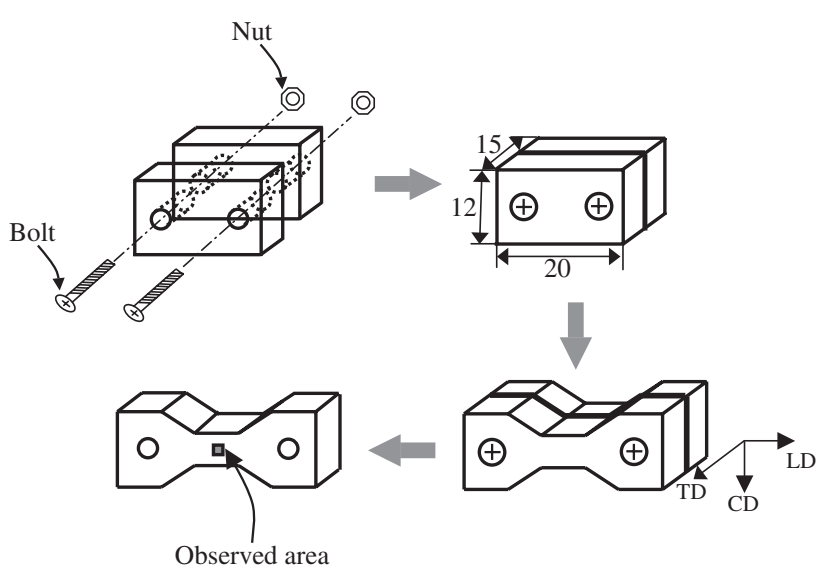

Fig. 2 Schematic drawing of compression test and observed area of deformed specimen.

lized region. ${ }^{13)}$ The specimen was quenched to room temperature by water jet immediately after the compression to freeze the deformed microstructure.

\subsection{Observation of microstructural characteristics}

The metallographic examination was performed by optical microscopy and scanning electron microscopy (SEM JEOL 5400). The microstructural observation was carried out on the center of the specimen parallel to the compressive direction, which is known to have a plane strain condition according to FEM analysis of this specimen geometry by Inoue et al., ${ }^{14)}$ as shown in Fig. 2. The specimens were first electropolished and etched for 20 seconds using a solution containing $\mathrm{HCl}$ (10 ml), $\mathrm{FeCl}_{3}(5 \mathrm{~g})$ and ethanol $(40 \mathrm{ml})$, by which $\{111\}$ planes were attacked most slowly and consequently revealed. The measurement of grain orientation was carried out by a scanning electron microscope (LEO Gemini 1550) equipped with TSL EBSD system. The specimens for the EBSD examination were ground with $\mathrm{SiC}$ papers and mechanically polished with a $1 \mu \mathrm{m}$ alumina paste, and then they were electrochemically polished for $20 \mathrm{~s}$ with a solution of $10 \%$ perchloric acid in ethanol.

\section{Results and Discussion}

\subsection{Strain distribution}

Figure 3 shows the change of the specimen shape by the hot compression test. The sides of specimen slightly bulged after compression (Fig. 3(b)). But the cross-section of the assembled specimen is relatively smooth compared with the sides (Fig. 3(c)). The cross-section could be investigated after a slight grinding. Therefore, if the microstructure of the cross-section before compression is observed, it becomes possible to compare the microstructures of identical grains before and after the hot compression test. Figure 4 shows one example of the deformed microstructure after $50 \%$ deformation at $1023 \mathrm{~K}$ and a strain rate of $1 / \mathrm{s}$. The micrograph corresponds to the hatched area of the deformed specimen. According to FEM analysis of this specimen geometry by Inoue et al. ${ }^{14)}$ there is a large plastic strain in the regions towards the anvil edges from the original point and the plastic strains in the $y$ direction show a plane strain condition $\left(\varepsilon_{x x}+\varepsilon_{y y}=0, \varepsilon_{z z}=0\right)$. In the present study, the investigation of strain was carried out along the compression axis, that is, in the y direction. The initial grain size, $d_{\mathrm{o}}$, at each position was measured. Then the experimental measurement of the compressive strain $\varepsilon_{y y}$ was carried out from $\ln \left(d / d_{\mathrm{o}}\right)$ by measuring the size, $d$, of the identical grain after hot compression test. The measured compressive strain $\varepsilon_{y y}$ was converted into the equivalent plastic strain $\varepsilon_{e q}$ using $2 / \sqrt{ } 3 * \varepsilon_{y y}$. Figure 5 shows the measured equivalent plastic strain and the calculated strain. The equivalent plastic strain obtained from the experimental measurement showed a good agreement with the calculated strain.

In this study, the positions in the range of $0-100 \mu \mathrm{m}$ from the center corresponding to the compressive strain range of 1.65-1.9 were chosen for investigating the effect of initial grain orientation on the evolution of the deformed microstructure after hot compression test.

\subsection{Deformed microstructure}

Figure 6(a) represents an initial microstructure of the specimen. The initial grain size is about $450 \mu \mathrm{m}$. The schematic drawing of Fig. 6(a) is shown in Fig. 6(b). Figure 6(c) shows the microstructure in the same region as Fig. 6(a) after $50 \%$ deformation at $1023 \mathrm{~K}$ and a strain rate of $1 / \mathrm{s}$. Figure 6(d) shows the schematic drawing of Fig. 6(c). The indexing numbers in Fig. 6 mean the identical grains before and after deformation. From Figs. 6(a) and (c), grains \#10, $\# 11$ and \#12 that are slightly deformed can be easily discriminated before and after deformation. Once some grains are discriminated, the neighboring grains like grain \#9 can be easily discriminated even though they are heavily deformed. In this way, we distinguished the identical grains before and after 50\% deformation. The laminar elongation of the structure is evidently parallel to the longitudinal direction as can be seen in Fig. 6(c). There are numerous dark etching shear bands lying at $30-40^{\circ}$ to the longitudinal direction across almost all the grains, signifying the localized inhomogeneous deformation. Even though the microstructure of grain \#1 is considerably elongated, no shear bands are observed. Figure 7 represents an SEM micrograph, which confirms the presence of shear bands in grain \#2 and their absence in grain \#1.

\subsection{Orientation analysis by EBSD}

As seen in Fig. 8(a), the optical micrograph shows the 

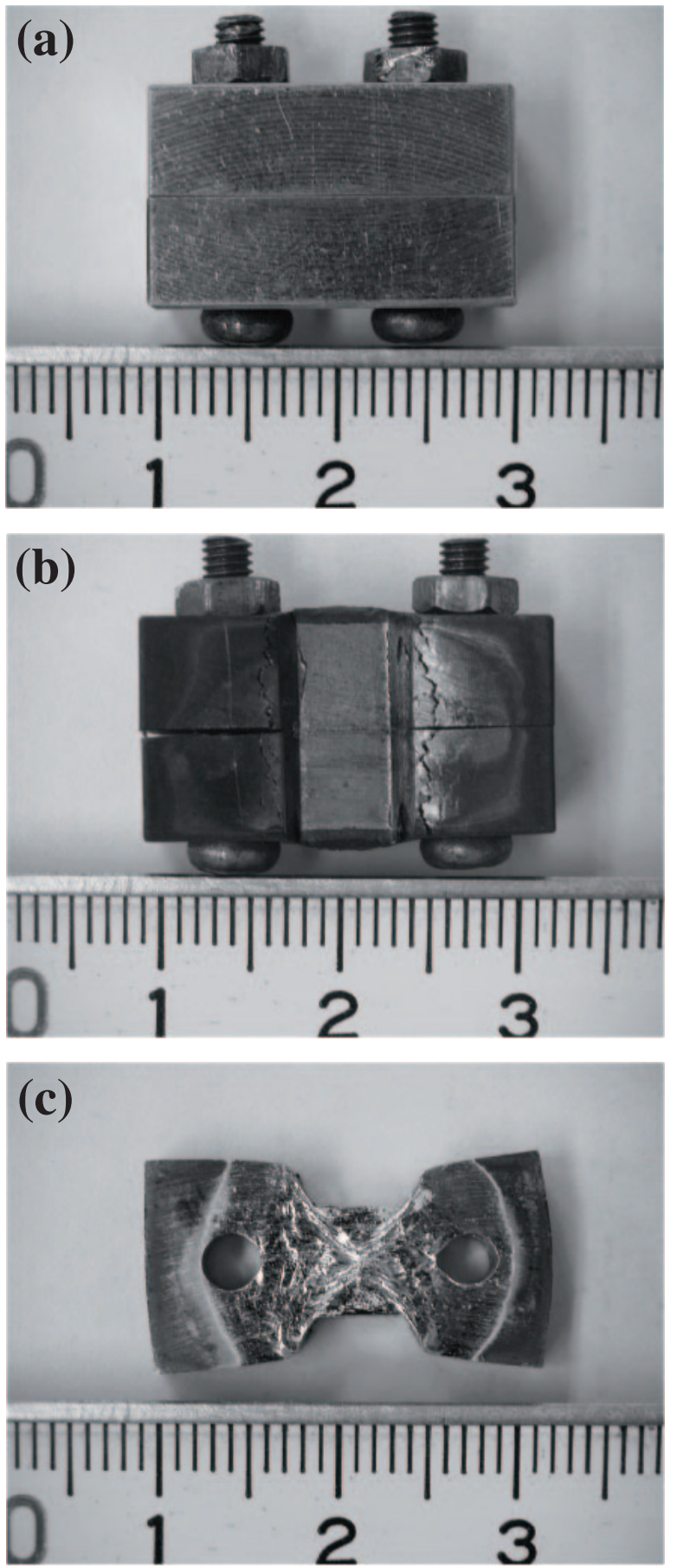

Fig. 3 Optical micrographs showing specimen shapes (a) before and (b) after hot compression test and (c) cross-section separated from assembled specimen.

magnified area including grains \#1 and \#2 deformed to a strain of about 1.65, indicated by the block in Fig. 6(c). Figure 8(b) shows the misorientation map of Fig. 8(a). In the EBSD map, high angle grain boundaries $\left(>15^{\circ}\right.$ misorientation between adjacent pixels) are depicted as red lines, while low angle boundaries $\left(<15^{\circ}\right)$ as blue lines. As seen in Fig. 8(b), the shear bands in grain \#2 produce sharply rotated small areas, whereas the region between these shear bands is deformed homogeneously. On the other hand, grain \#1 does not reveal any heterogeneity or orientation splitting on a macroscopic scale even after the deformation to an equiv-
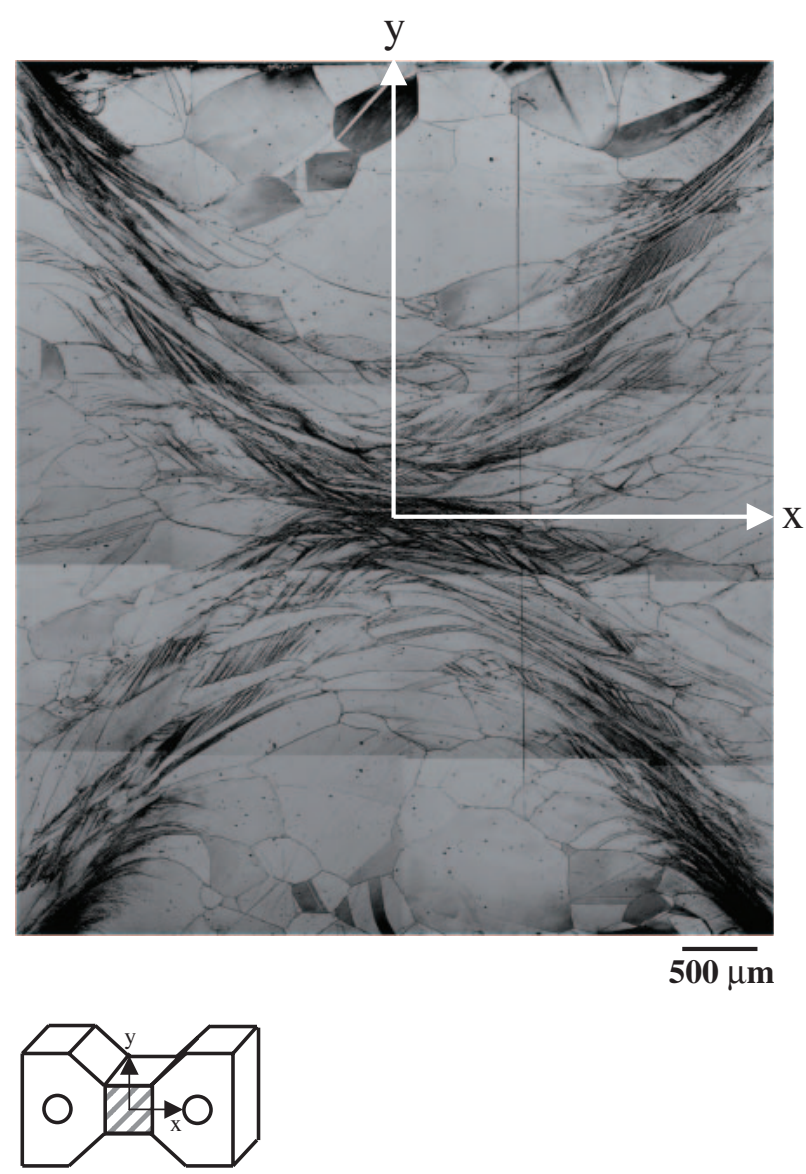

Fig. 4 Optical micrograph showing microstructure of cross-section after $50 \%$ deformation at $1023 \mathrm{~K}$ and strain rate of $1 / \mathrm{s}$.

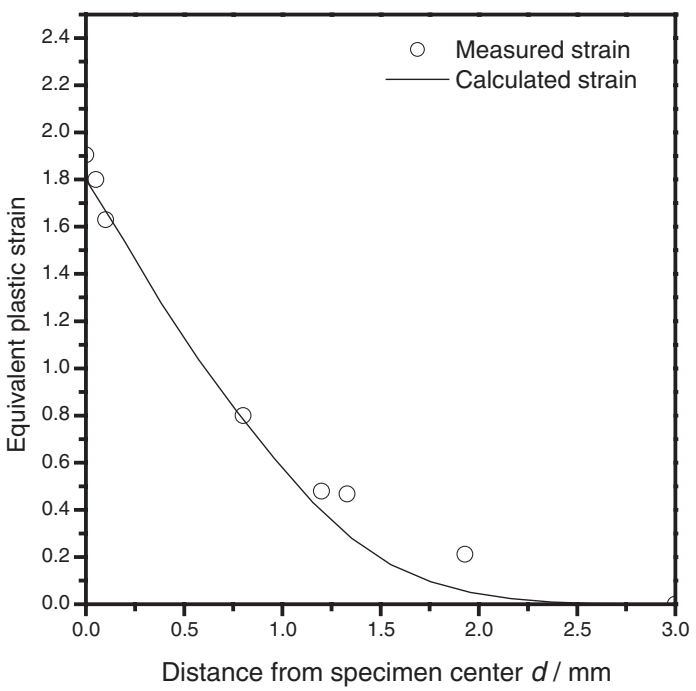

Fig. 5 Distribution of equivalent plastic strain along the compression axis after $50 \%$ deformation at $1023 \mathrm{~K}$ and strain rate of $1 / \mathrm{s}$.

alent plastic strain of 1.65. This is different from Korbel and Martin's theory ${ }^{15)}$ that shear bands generate large stress concentrations at their tips which may eventually enable them to penetrate a neighboring grain.

The misorientation distributions within grains \#1 and \#2 determined from the EBSD maps are shown in Fig. 9. The 

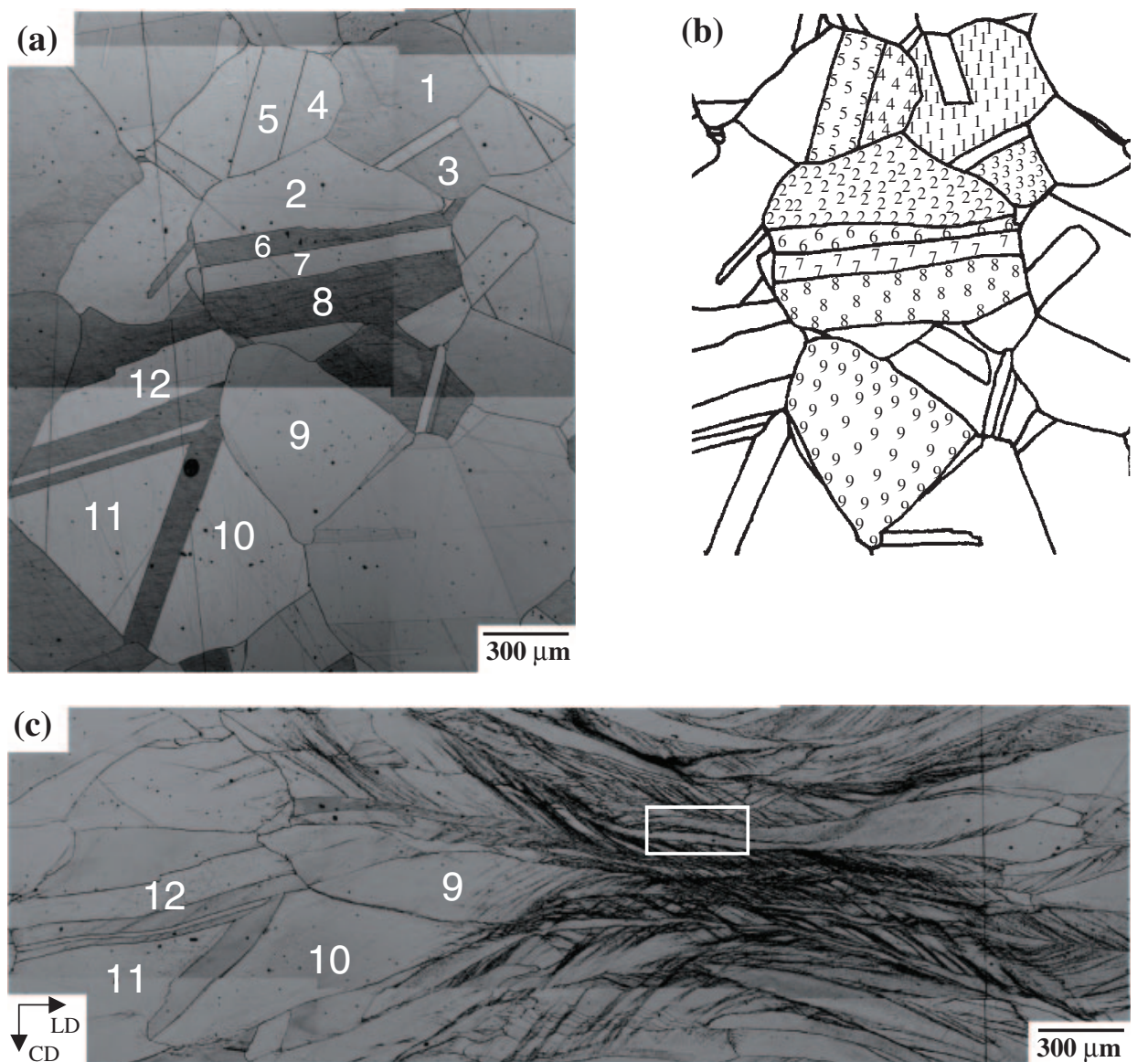

(d)

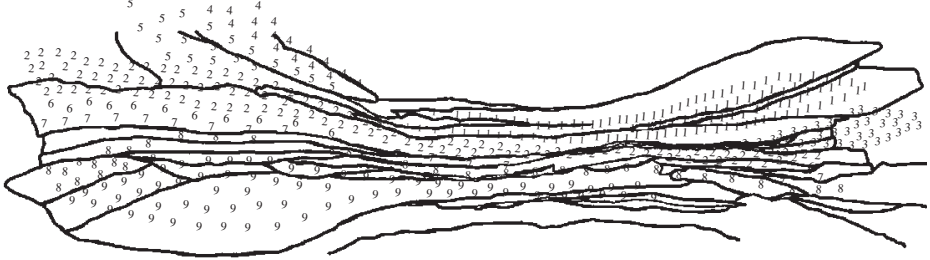

Fig. 6 Optical micrographs showing microstructures of identical area (a) before and (c) after $50 \%$ deformation at $1023 \mathrm{~K}$ and strain rate of 1/s. (b) and (d) are schematic illustrations of (a) and (c), respectively. Microstructure within white frame corresponds to Fig. 8.

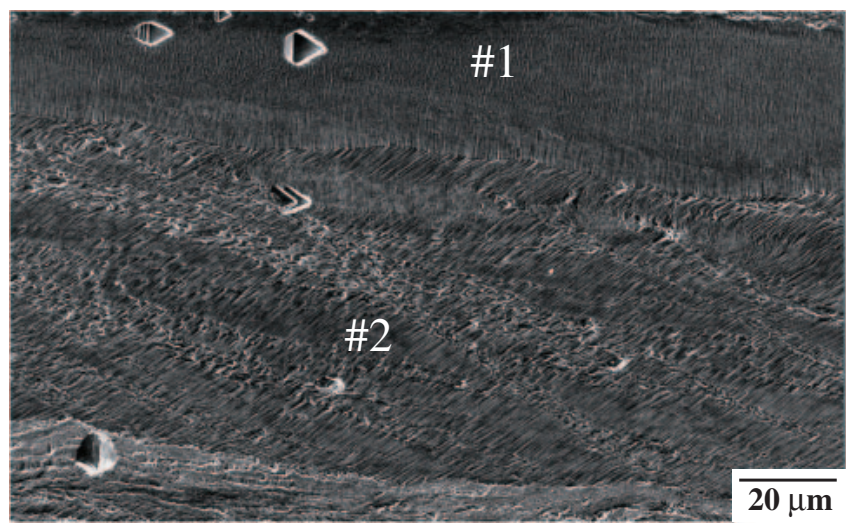

Fig. 7 SEM micrograph showing microstructure of grains \#1 and \#2 in Fig. 6(c).

graphs show the relative frequency of misorientations at intervals of $3^{\circ}$. Misorientations less than $1.5^{\circ}$ are omitted due to the orientation noise in EBSD measurements. The fraction of misorientation angle for grain \#1 exists only in a low angle
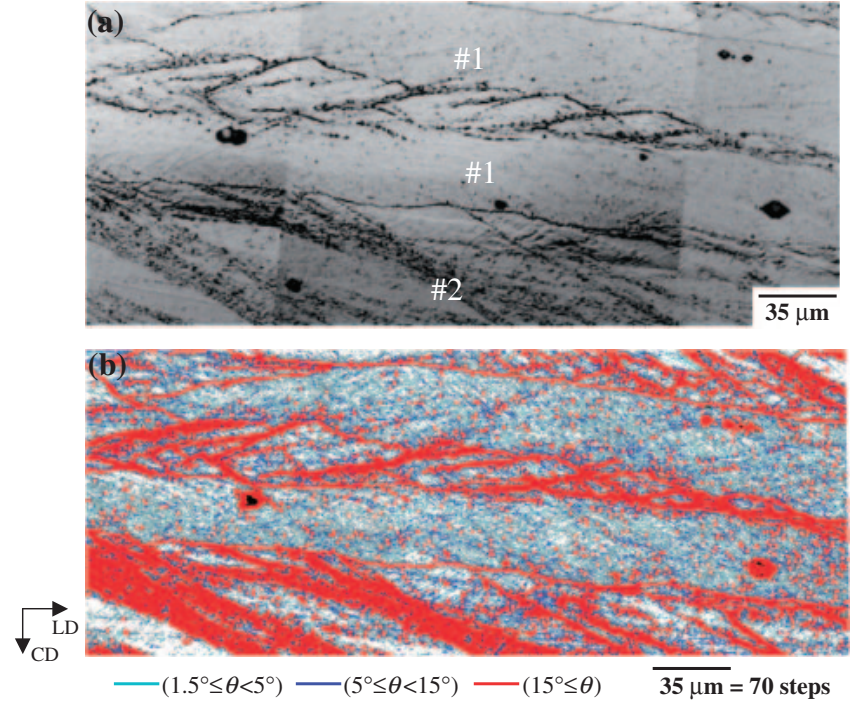

Fig. 8 (a) optical micrographs showing magnified view of area indicated by block shown in Fig. 6(c) and (b) misorientation map between adjacent pixels. 


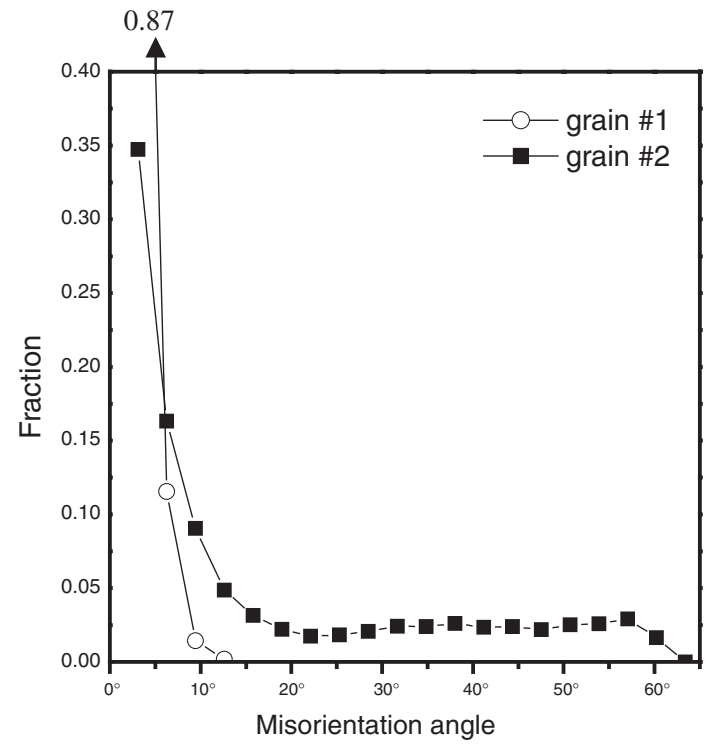

Fig. 9 Misorientation distributions within grains \#1 and \#2.

grain boundary region $\left(<15^{\circ}\right)$. On the contrary, the misorientation distribution within grain \#2 spreads out to a high angle grain boundary region as large as $60^{\circ}$.

In general, shear bands have been observed to form as microstructural inhomogeneities at large strains during plastic deformation. It has been observed that shear bands are capable of storing large shear strains in the deformation process and, consequently, producing high local dislocation densities. ${ }^{16,17)}$ These shear bands are thought to serve as favorable nucleation sites upon recrystallization that occurs during subsequent annealing, and thus have a very important effect on microstructural properties such as recrystallized grain size and texture. Macroscopic properties of shear bands seem to be greatly affected by the macroscopically imposed deformation variables that include strain, strain rate, temperature, grain size, etc.

In the present experiment, the deformation parameters of each grain are absolutely the same except the initial orientation of grains. Therefore, regarding the formation of shear bands, an important observation in this study is that the presence or absence of shear bands seems to depend on the initial grain orientation, as can be seen in Fig. 8. So we will below seek to make clear the reason for the homogeneous deformation of grains even after deformation of high compression strains.

Figure 10(a) represents the initial orientations of 14 grains as $\{100\}$ pole figure, showing shear bands after deformation. On the other hand Fig. 10(b) presents the initial orientations of 13 grains that show no heterogeneities such as shear bands even after deformation to equivalent plastic strains of 1.65 1.9 at $1023 \mathrm{~K}$ and a strain rate of $1 / \mathrm{s}$. The pole figure was determined from the average value of the Euler angles of each grain before deformation processing. As seen in Fig. $10(a)$, in case of the initial orientations of grains with shear bands, it seems that the near $\{110\}\langle 111\rangle$ orientation exists as a main component. To the contrary, in case of the initial orientations of grains showing no shear bands after deformation, most of the initial orientations are clustered around

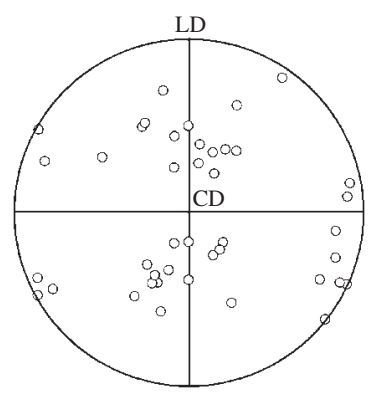

(a)

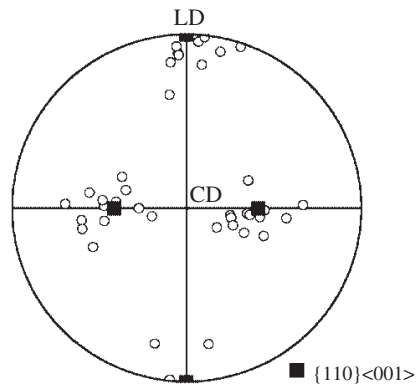

(b)
Fig. $10\{100\}$ pole figures of initial orientations of grains showing (a) shear bands and (b) no shear bands after 50\% deformation at $1023 \mathrm{~K}$ and strain rate of $1 / \mathrm{s}$.

$\{110\}\langle 001\rangle$ orientation (Goss orientation) with a maximum deviation angle of $27.5^{\circ}$ from $\{110\}\langle 001\rangle$.

In general, a deformed single crystal is divided into being either stable or unstable. ${ }^{18)}$ The Goss (011)[100] and Brass (011)[21 $\overline{1}]$ orientations are examples of stable orientations. Their deformation orientations do not spread from the starting orientations even after high strains. On the other hand, the Cube (001)[100] and ND rotated Cube (001)[110] orientations comprise unstable orientations. These orientations are known to develop shear bands that lead to a large scattering from the starting orientation.

In a crystal with the (011)[100] initial orientation, the active slip systems are (111)[10 $\overline{1}],(111)[1 \overline{1} 0],(\overline{1} 11)[101]$ and (111)[110]. ${ }^{19)}$ The coplanar slip of equal magnitude on each of the four slip systems is expected, which produces self-compensating orientation changes. Such a deformation mode is known to lead to a uniform dislocation microstructure without heterogeneities such as shear bands. Ferry and Humphreys ${ }^{20)}$ showed that single phase crystals of Al$0.05 \% \mathrm{Si}$ of $\{110\}\langle 001\rangle$, deformed in plane strain compression, are stable up to true strains of 3.0.

Considering that the division of grains into stable or unstable orientations refers essentially to the room-temperature behavior, the stability of grains may be affected by deformation temperature. Actually, Maurice et al. ${ }^{21)}$ investigated the influence of deformation temperature on the stability of the Cube (001)[100] orientation of Al and Al$1 \% \mathrm{Mn}$ crystals at $473-673 \mathrm{~K}$. They showed that the behavior of the cube orientation is dependent on temperature and strain rate. That is, at $T<573 \mathrm{~K}$ the decomposition into bands of octahedral slip occurs to lead the cube-oriented crystal unstable whereas at higher temperature the cube orientation is deformed by double slip on $\{110\}\langle 1 \overline{1} 0\rangle$ systems and is stable up to high strain of 1.5. As a result, in case of the Goss (011)[100] orientation that is more stable than the Cube orientation at room temperature, it is very presumable in this study that the homogeneous deformation can be expected at high temperature in grains with a little deviation angle from the ideal Goss orientation.

\section{Conclusion}

The effect of grain orientation on deformed microstructure in the Ni-30Fe alloy after hot deformation to equivalent 
plastic strains of $1.65-1.9$ at $1023 \mathrm{~K}$ and a strain rate of $1 / \mathrm{s}$ was investigated and the following results were obtained.

(1) The presence or absence of shear bands depended on the initial orientations of grains.

(2) Some grains did not reveal any heterogeneity or orientation splitting on a macroscopic scale even after deformation to an equivalent plastic strain of 1.9 .

(3) Most of the initial orientations of grains which showed no shear band after deformation were clustered around the Goss $\{110\}\langle 001\rangle$ orientation with a maximum deviation angle of $27.5^{\circ}$ from $\{110\}\langle 001\rangle$.

(4) The homogeneous deformation could be expected at high temperature in grains with a little deviation angle from the ideal Goss orientation.

\section{Acknowledgements}

The authors would like to thank Ms. Sakurai, NIMS, for her help with EBSD experiment. One of the authors (J.Y.C) was supported by the Post-doctoral Fellowship Program of KOREA SCIENCE \& Engineering Foundation (KOSEF) and wishes to express sincere gratitude to the Steel Research Center, NIMS.

\section{REFERENCES}

1) C. M. Li, H. Yada and H. Yamagata: ISIJ Int. 39 (1999) 209-211.
2) P. J. Hurley, B. C. Muddle and P. D. Hodgson: Metall. Mater. Trans. 33A (2002) 1019-1026.

3) M. R. Hickson, P. J. Hurley, R. K. Gibbs, G. L. Kelly and P. D. Hodgson: Metall. Mater. Trans. 33A (2002) 1019-1026.

4) R. Z. Valiev, A. V. Korznikov and R. R. Mulyukov: Mater. Sci. Eng. A168 (1993) 141-148.

5) D. H. Shin, B. C. Kim, K.-T. Park and W. Y. Choo: Acta Mater. 48 (2000) 3245-3252.

6) Y. Saito, N. Tsuji, H. Utsunomiya and T. Sakai: Acta Mater. 47 (1999) 579-583.

7) A. Belyakov, T. Sakai, H. Miura and R. Kaibyshev: ISIJ Int. 39 (1999) 592-599.

8) W. Chranock and J. Nutting: Met. Sci. J. 1 (1967) 123-127.

9) P. J. Hurley, B. C. Muddle, P. D. Hodgson, C. H. J. Davies, B. P. Wynne, P. Cizek and M. R. Hickson: Mater. Sci. Forum 284-286 (1998) 159-166.

10) Y. Adachi: CAMP-ISIJ 12 (1999) 1123.

11) D. W. Suh, S. Torizuka, A. Ohmori, T. Inoue and K. Nagai: ISIJ Int. 42 (2002) 432-439.

12) N. Hansen: Metall. Mater. Trans. 32A (2001) 2917-2935.

13) P. J. Hurley, B. C. Muddle and P. D. Hodgson: Metall. Mater. Trans. 32A (2001) 1507-1517.

14) T. Inoue, S. Torizuka, K. Nagai, K. Tsuzaki and T. Ohashi: Meter. Sci. Tech. 17 (2001) 1580-1588.

15) A. Korbel and P. Martin: Acta Mater. 34 (1986) 1905-1909.

16) A. A. Ridha and W. B. Hutchinson: Acta Mater. 30 (1982) 1929-1939.

17) A. Duckham, R. D. Knutsen and O. Engler: Acta Mater. 49 (2001) 2739-2749.

18) A. Mecif, B. Bacroix and P. Franciois: Acta Mater. 45 (1997) 371-381.

19) J. Hirsch and K. Lücke: Acta Mater. 36 (1988) 2883-2904.

20) M. Ferry and F. J. Humphreys: Acta Mater. 44 (1996) 1293-1308.

21) C. Maurice and J. H. Driver: Acta Mater. 45 (1997) 4627-4638. 